\title{
Adequação nutricional do almoço self-service de uma empresa de Santa Luzia, MG'
}

\author{
Nutritional adequacy of a company's self-service \\ lunch in Santa Luzia, state of Minas Gerais, Brazil
}

Maria Marta Amancio AMORIM²

Roberto Gonçalves JUNQUEIRA ${ }^{3}$

Lieselotte JOKL ${ }^{3}$

\section{RE S U M O}

\section{Objetivo}

Avaliar a adequação nutricional dos cardápios do almoço self-service de uma empresa, tomando-se como base o consumo médio diário per capita.

\section{Métodos}

Empregou-se o método da pesagem direta dos ingredientes, preparações, bebidas e sobras, antes e após a distribuição das refeições.

\section{Resultados}

O valor energético médio, corrigido pelo índice-de-rejeito (6,6\%), foi de $1108 \mathrm{kcal}$. Os teores de carboidratos, proteínas e lipídios forneceram, respectivamente, 51,0\%, 19,0\% e 30,0\% de energia metabolizável. Com base nas recomendações para a população brasileira do sexo masculino $(2785 \mathrm{kcal})$, os cardápios avaliados contribuíram com 40,0\% da necessidade energética total, 30,0\% dos carboidratos, 96,0\% das proteínas e $47,0 \%$ dos lipídios. Para a população do sexo feminino $(2056 \mathrm{kcal}$ ), os valores correspondentes foram, respectivamente, $54,0 \%, 41,0 \%, 130,0 \%$ e $64,0 \%$. O consumo de fibra alimentar mostrou-se inadequado e correspondeu a $48,0 \%$ das necessidades diárias da clientela.

\footnotetext{
1 Artigo baseado na dissertação em Ciência de Alimentos de M.M.A. AMORIM. "Adequação nutricional do almoço self service de uma empresa do município de Santa Luzia, MG”. Faculdade de Farmácia, Universidade Federal de Minas Gerais, 2002.

2 Curso de Pós-Graduação em Ciência de Alimentos, Universidade Federal Minas Gerais; Centro Universitário Newton Paiva. Av. Silva Lobo, 1750, Nova Granada, 30460-000, Belo Horizonte, MG, Brasil. Correspondência para/Correspondence to: M.M.A. AMORIM. E-mail: <martamorim.prof@newtonpaiva.br>.

3 Departamento de Alimentos, Faculdade de Farmácia, Universidade Federal Minas Gerais. Av. Antonio Carlos, 6627, 31270-901, Belo Horizonte, MG, Brasil.E-mail: <junkeira@dedalus.lcc.ufmg.br; lisejokl@ufmg.br>.
} 


\section{Conclusão}

Os usuários desta empresa necessitam receber orientações nutricionais sobre alimentação adequada, pois o almoço consumido foi hipoglicídico, hiperprotéico e hiperlipídico. Enquanto foi normocalórico para os homens, mostrou-se hipercalórico para as mulheres.

Termos de indexação: almoço self-service, serviços de alimentação, nutricionista, unidade de alimentação e nutrição.

\section{A B S T R A C T}

\section{Objective}

To evaluate the nutricional adequacy of a company's self-service lunch menus, based on the daily mean per capita consumption.

\section{Methods}

The method used was the direct weighing of ingredients, meal dishes, beverages and leftovers, before and after meal distribution.

\section{Results}

The average energetic value corrected by the plate waste factor (6.6\%) was equal to $1108 \mathrm{kcal}$. The carbohydrate, protein, and fat contents supplied, respectively, 51\%, 19\%, and 30\% of the metabolic energy. Based on recommendations for the Brazilian male population (2 785kcal), the evaluated lunch menus corresponded to $40 \%$ of energy, $30 \%$ of carbohydrate, $96 \%$ of protein, and $47 \%$ of lipids. For the female clientele, those values were, respectively, 54\%, 41\%, 130\%, and $64 \%$. The consumption of dietary fiber was inadequate, corresponding to $48 \%$ of the clientele's daily requirements.

\section{Conclusion}

The usual consumers of the above mentioned self-service lunch should receive nutritional advice about appropriate meals, since the evaluated lunch consumption was low in carbohydrates, high in protein and lipids. Though it might be normocaloric for the men, it was hypercaloric for the women.

Indexing terms: self-service lunch, food services, nutritionist, food and nutrition sevices.

\section{N T R O D U Ç Ã O}

As Unidades de Alimentação e Nutrição (UAN) têm como objetivo principal oferecer alimentação adequada às necessidades nutricionais da clientela das empresas ${ }^{1}$. Os cardápios elaborados devem ser, portanto, balanceados de modo que os requerimentos em energia e nutrientes possam ser atendidos², garantindo saúde e capacitação para o trabalho. As preparações culinárias de cada refeição devem ser selecionadas pelo nutricionista, levando em consideração os hábitos e as preferências alimentares da clientela, a safra, a oferta e o custo do gênero alimentício no mercado, os recursos humanos, a disponibilidade de área e equipamentos, o preparo e o consumo efetivo dos alimentos.

Para assegurar a adequação nutricional do almoço fornecido para a clientela da UAN, é preciso estabelecer o quanto o consumo médio corresponde às recomendações ${ }^{2}$, ou seja, se a média do que é consumido pelos clientes atende às necessidades nutricionais de um indivíduo-médio, que apresente as características preva- 
lentes da clientela. As diferenças individuais são definidas pelas quantidades consumidas per capita, sendo dependentes do sistema de distribuição adotado pela UAN - porcionado por atendentes ou tipo self service (o cliente se serve) ${ }^{1}$. No sistema porcionado, o cliente opta por consumir a porção pré-definida das preparações disponíveis. Já no self service total não existem restrições das quantidades servidas. Portanto, neste tipo de UAN - uma tendência atual de mercado - o nutricionista deve estar atento ao consumo médio elevado de alguns alimentos, principalmente das carnes e gorduras.

As refeições caracterizadas pelo excesso de alimentos com elevada densidade energética e/ou baixa quantidade de fibras, o aumento na ingestão de açúcares e gorduras, principalmente as de origem animal, além da maior incorporação às refeições de produtos industrializados, acarretaram modificações na alimentação brasileira, evidenciadas na década de 1990 pelo estudo multicêntrico e pela pesquisa sobre o orçamento familiar ${ }^{3}$. Entretanto, estes estudos de representatividade nacional, envolveram elevado número de indivíduos, e seus resultados podem diferir dos obtidos em pesquisa realizada com grupos menores e específicos. Portanto, a avaliação do consumo do indivíduo-médio de uma UAN com almoço self service total, é importante, tanto para verificar a adequação nutricional do almoço em questão, como para estabelecer parâmetros locais de consumo.

Entre as diversas metodologias existentes para determinar o consumo alimentar médio, a da pesagem direta foi adotada neste estudo, por parecer a mais sensível e confiável ${ }^{4}$. Apesar de este método demandar mais tempo na coleta dos dados ${ }^{5}$, com ele obtêm-se valores necessários ao planejamento, à organização, ao controle e à avaliação, tanto dos processos operacionais da UAN, quanto da adequação nutricional da refeição servida.

Esta metodologia foi usada no Estudo Nacional de Despesa Familiar e consistiu na pesagem dos alimentos a serem consumidos, das sobras e da parcela não-comestível de todas as refeições das famílias ${ }^{6}$. Dados como estes poderão ser facilmente coletados na UAN, onde normalmente ocorre a pesagem diária dos gêneros alimentícios utilizados no preparo das refeições. No entanto, para obter resultados mais precisos é, também, necessário pesar as preparações prontas, as sobras (preparações totais nãodistribuídas) e os rejeitos (restos no prato do cliente). O último, porém, deve ser triado quanto aos ossos das carnes e às cascas de frutas'. Cumpre ressaltar que, na literatura nacional pesquisada, foram avaliados ora um ora outro destes parâmetros, sem associar um ao outro ${ }^{7-12}$. Assim, a adequação nutricional média do almoço self service total de uma UAN, localizada no município da Região Metropolitana de Belo Horizonte, foi avaliada com base no método de pesagem direta modificado, e comparada com os dados correlatos nacionais existentes.

\section{MATERIALE MÉTODOS}

\section{Coleta de dados}

A empresa avaliada está localizada no município de Santa Luzia, MG. Avaliaram-se as preparações dos cardápios de almoço self service total da sua UAN, oferecidos no período de 8 de janeiro a 14 de março de 2001.

Cada gênero alimentício utilizado no preparo das refeições, após retiradas as aparas não-comestíveis, foi pesado, usando-se balança de prato Gural ${ }^{\circledR}$, capacidade $20 \mathrm{~kg}$, com divisões de 20g; para os líquidos, usou-se proveta de $500 \mathrm{~mL}$, com graduações de $5 \mathrm{~mL}$. O sal empregado não foi pesado. As preparações foram pesadas antes e ao final da distribuição (respectivas sobras) na mesma balança. Os pesos dos utensílios destinados ao acondicionamento dos alimentos crus e das preparações prontas foram descontados dos pesos dos ingredientes ou das preparações. As quantidades de ingredientes contidas na sobra de cada preparação foram obtidas por cálculo 
proporcional a partir da respectiva preparação inicial. Estes teores foram, em seguida, deduzidos das quantidades iniciais, resultando no consumo real pela clientela (Tabela1).

Os sucos concentrados, o café e o leite foram medidos diariamente com o auxílio de jarras plásticas, capacidade de 1 litro com graduações de $100 \mathrm{~mL}$. Os sucos concentrados (de diversos sabores) - sendo dois adoçados e um diet - foram reconstituídos, utilizando-se os fatores de diluição 1:9,4 e 1:6, respectivamente. Os consumos médios dos diferentes sabores de refrigerantes foram obtidos, pesando-se, no início e término de duas semanas alternadas, os cilindros contendo os respectivos xaropes. Para essa pesagem, usou-se a balança de plataforma Semco ${ }^{\circledR}$, capacidade $200 \mathrm{~kg}$ com divisões de $1 \mathrm{~kg}$. Foram aplicados os fatores de diluição: 1:5,4 para os sabores à base de cola, limão e guaraná; e 1:4,4 para o de laranja.

O rejeito também foi pesado na balança Gural $^{\circledR}$. Os pesos dos ossos e das cascas foram descontados daqueles do rejeito e da refeição distribuída'. O índice de rejeito foi utilizado para avaliar o consumo real da refeição, correspondendo à razão percentual entre o peso do rejeito e o da preparação distribuída.

\section{Cálculo teórico dos macronutrientes e da fibra alimentar}

Os consumos reais per capita das preparações e bebidas, assim como os dos ingredientes usados, foram obtidos pela divisão dos totais pelo número de clientes servidos naquele dia. Os pesos dos ossos das carnes e das cascas das frutas foram deduzidos dos respectivos quantitativos dos ingredientes. Os teores correspondentes em macronutrientes foram obtidos de tabelas de uso corrente, privilegiando-se a tabela da Universidade de São Paulo, por conter valores resultantes de análises de produtos nacionais - e compilados adequadamente para a pesquisa ${ }^{13}$. Alguns alimentos crus estavam registrados sob a forma cozida nas tabelas originais. Portanto, o peso de cada um dos alimentos, como a acelga, a batata inglesa, a couve, o espinafre, a lentilha, o macarrão e a mostarda, foi convertido em seu correspondente cozido, utilizando-se os fatores de cocção (peso cozido da preparação/peso total dos ingredientes da preparação) obtidos na UAN: 0,64; 0,$93 ; 0,72 ; 0,69 ; 2,00 ; 2,76$ e 0,85, respectivamente. Para os alimentos não registrados nessas tabelas, empregaram-se os dados fornecidos pelo fabricante.

Tabela 1. Conversão do total de sobra da sopa de mandioca em seus respectivos ingredientes.

\begin{tabular}{lccc}
\hline \multirow{2}{*}{ Ingredientes } & \multicolumn{3}{c}{ Sopa de mandioca (kg ou L) } \\
\cline { 2 - 3 } & Preparação & Sobra & Consumido \\
\hline Mandioca & 18,200 & 5,850 & 12,350 \\
Óleo & 0,650 & 0,210 & 0,440 \\
Alho & 0,153 & 0,049 & 0,104 \\
Caldo galinha & 0,092 & 0,030 & 0,062 \\
Pimentão & 0,119 & 0,038 & 0,081 \\
Cebola & 0,117 & 0,038 & 0,079 \\
\hline Total & 19,331 & 6,215 & 13,116 \\
\hline Água & q.S.p. & & 21,000 \\
Peso após cocção & 30,950 & 9,950 & \\
Fator de cocção'. & 1,600 & & \\
\hline
\end{tabular}

1 Peso após o preparo/peso total dos ingredientes. 
Em seguida, os teores dos macronutrientes foram convertidos em quilocalorias, por meio dos fatores de Atwater para determinar o valor energético total (VET) médio, per capita, do almoço (preparações e bebidas). Os teores de fibra alimentar dos ingredientes foram obtidos pela mesma forma descrita. Os níveis médios reais per capita do VET, dos respectivos macronutrientes e da fibra alimentar das preparações e do almoço foram calculados empregando-se o índice de rejeito.

\section{Avaliação da adequação nutricional do almoço}

A adequação nutricional do almoço consumido pela clientela da UAN foi estabelecida com base na contribuição do VET médio real per capita do almoço, em relação às necessidades energéticas totais (NET) do indivíduo-médio, preconizadas pela Sociedade Brasileira de Alimentação e Nutrição (SBAN) ${ }^{2}$. Com esta finalidade, selecionou-se um grupo representativo da clientela da UAN. Para os adultos de ambos os sexos, estabeleceram-se as faixas etárias e, com base na tabela elaborada para o percentil 97 da população, calcularam-se as respectivas médias das NET ${ }^{14}$.

Para averiguar a adequação dos macronutrientes foram empregados os percentuais médios em relação à NET: $67 \%$ para os carboidratos, $8 \%$ para a proteína e $25 \%$ para os lipídios². Além disto, a contribuição dos macronutrientes ao VET real médio per capita do almoço, foi correlacionada ao percentual estabelecido em função das recomendações segundo as necessidades nutricionais ${ }^{15}: 40 \%$ da NET para esta refeição, considerando que a UAN estudada não fornece o desjejum, nem os lanches intermediários. A quantidade de fibra alimentar consumida foi comparada com a recomendação de ingestão diária, $20 \mathrm{~g}$ a $25 \mathrm{~g}^{2,14}$.

\section{RES U LT A D O S}

A clientela da UAN foi constituída por 310 funcionários, na faixa etária compreendida de 16 a 60 anos. Os 22 cardápios estudados no período, servidos de segunda a sexta-feira, foram representativos do padrão alimentar da UAN.

As refeições foram compostas por cinco tipos de saladas; um prato principal e sua opção preparados com carne bovina ou suína e de aves ou peixes - e ovos; três guarnições, sendo arroz e feijão fixos; duas sobremesas: sendo doce e fruta; bebidas - refrigerantes, sucos concentrados, leite e café; temperos - azeite, vinagre e molhos; e, como complementos - pão francês e farinhas. As quantidades médias da preparação total produzida, da sobra, da casca, do osso e das preparações distribuídas (quantidade total e per capita) são apresentadas na Tabela 2.

O consumo médio total per capita de bebida durante a refeição foi de $134 \mathrm{~mL}$ de refrigerante $(58 \mathrm{~mL}$ cola $+37 \mathrm{~mL}$ laranja $+18 \mathrm{~mL}$ guaraná $+21 \mathrm{~mL}$ limão) e $23 \mathrm{~mL}$ do light (sabor cola). Quanto ao suco adoçado, foi de $190 \pm 40 \mathrm{~mL}$ $(\mathrm{CV}=21 \%)$ e do diet, $6 \pm 2 \mathrm{~mL}(\mathrm{CV}=31 \%)$. Constatou-se, também, que o consumo de leite foi igual a $2 \mathrm{~mL} \pm 1$.

Tabela 2. Quantidades médias das preparações e das sobras.

\begin{tabular}{lrrrrrrr}
\hline & \multirow{2}{*}{$\mathrm{n}^{1}$} & Preparação produzida $(\mathrm{kg})$ & Sobras $(\mathrm{kg})$ & Cascas $^{2}(\mathrm{~kg})$ & Ossos $^{2}(\mathrm{~kg})$ & \multicolumn{2}{c}{ Preparação distribuída } \\
\cline { 5 - 7 } & & & & & \multicolumn{2}{c}{ Total $(\mathrm{kg})$} & Per capita $(\mathrm{g})$ \\
\hline Médias & 308,0 & 218,0 & 23,0 & 7,0 & 8,0 & 186,0 & 0,609 \\
DP & 35,0 & 23,6 & 8,2 & 4,0 & 4,5 & 19,8 & 0,060 \\
CV\% & 11,0 & 11,0 & 36,0 & 55,0 & 55,0 & 11,0 & 10,000 \\
\hline
\end{tabular}

${ }^{1}$ Número de refeições/dia; ${ }^{2}$ Média calculada considerando apenas os dias em que ocorreram as sobras. 
Notam-se na Tabela 3, consumos médios, per capita, das refeições e bebidas, assim como o índice de rejeito médio da preparação distribuída.

Observou-se que os teores totais médios de carboidratos, proteínas e lipídios consumidos per capita foram de $147 \pm 17 \mathrm{~g}(\mathrm{CV}=11,0 \%)$, $57 \pm 11 \mathrm{~g}(\mathrm{CV}=18,0 \%)$ e $39 \pm 10 \mathrm{~g}(\mathrm{CV}=26,0 \%)$. Quando estes foram convertidos em quilocalorias, corresponderam a $50,0 \%, 30,0 \%$, e $20,0 \%$ do VET, respectivamente, totalizando $1171 \pm 145 \mathrm{kcal}$ ( $C V=12,0 \%$ ). O nível de fibra alimentar contida nas preparações dos cardápios estudados foi igual a $10 \pm 1 \mathrm{~g}(\mathrm{CV}=13,0 \%)$. Após a correção pelo índice de rejeito (6,6\%), esses dados constituíram a Tabela 4, sendo discriminados por preparações. Com base no consumo real total per capita de alimentos, o almoço ingerido pela clientela da UAN correspondeu ao VET de $1108 \mathrm{kcal}$, provenientes de carboidratos (564kcal), proteínas (214kcal) e lipídios (329kcal).

O grupo representativo selecionado para a avaliação da adequação nutricional do almoço foi constituído por 116 homens e 65 mulheres, na faixa etária de 16 a 69 anos. Dentre eles, a maioria encontrava-se na faixa etária de 25 a 50 anos, sendo $60 \%$ e $65 \%$ nas dos sexos masculino e feminino, respectivamente. Desta forma, o indivíduo-médio desta UAN representou 58\% da totalidade dos seus clientes. As NET médias²,14 corresponderam a $2785 \mathrm{kcal}$ para o indivíduo-médio masculino e a $2056 \mathrm{kcal}$ para as mulheres. Na Tabela 5 indica-se a adequação nutricional do almoço médio, per capita corrigido, e a correção pelo índice de rejeito, em relação às necessidades energéticas totais e aos respectivos macronutrientes, discriminada por sexo do indivíduo-médio da UAN estudada.

Tabela 3. Consumo médio per capita de alimento no almoço.

\begin{tabular}{|c|c|c|c|c|c|c|}
\hline & \multirow{2}{*}{$\begin{array}{l}\text { Preparação } \\
\text { distribuída }\end{array}$} & \multirow{2}{*}{ Rejeito $^{1}(\mathrm{~g})$} & \multirow{2}{*}{ Índice-de- rejeito $2(\%)$} & \multicolumn{3}{|c|}{ Consumo per capita } \\
\hline & & & & Refeição real ${ }^{3}(\mathrm{~g})$ & Bebida $(\mathrm{mL}=\mathrm{g})$ & Total (g) \\
\hline Médias & 609,0 & 40,0 & 6,6 & 569,0 & 354,0 & 923,0 \\
\hline DP & 63,5 & 10,4 & 1,5 & 59,8 & 39,9 & 65,0 \\
\hline CV\% & 10,0 & 26,0 & 24,0 & 11,0 & 11,0 & 7,0 \\
\hline
\end{tabular}

${ }^{1}$ Isento de cascas e ossos (3g); 2 ("Rejeito"/preparação distribuída) x 100; ${ }^{3} \mathrm{O}$ "rejeito" foi subtraído da preparação distribuída.

Tabela 4. Consumo real de alimento e níveis de VET, macronutrientes e fibra alimentar médios per capita.

\begin{tabular}{|c|c|c|c|c|c|c|}
\hline Preparação & Consumo ou $(\mathrm{mL})$ & $\operatorname{VET}^{1}$ (kcal) & Carboidrato (g) & Proteína (g) & Lipídio (g) & Fibra alimentar (g) \\
\hline Prato protéico & 129,0 & 393,0 & 10,4 & 40,6 & 21,0 & 0,8 \\
\hline Guarnição & 61,0 & 76,0 & 8,4 & 2,1 & 3,8 & 1,0 \\
\hline Arroz & 108,0 & 178,0 & 35,4 & 3,2 & 2,6 & 0,9 \\
\hline Feijão & 67,0 & 61,0 & 8,1 & 3,5 & 1,7 & 3,9 \\
\hline Salada & 113,0 & 62,0 & 5,8 & 1,8 & 3,4 & 2,2 \\
\hline Sobremesa & 79,0 & 81,0 & 15,3 & 1,3 & 1,6 & 0,7 \\
\hline Tempero & 12,0 & 32,0 & 2,4 & 0,3 & 2,4 & 0,2 \\
\hline Total & 569,0 & 883,0 & 85,8 & 52,8 & 36,5 & 9,7 \\
\hline Bebida & 354,0 & 224,6 & 55,3 & 0,7 & 0,1 & 0,0 \\
\hline Total geral & 923,0 & 1108,0 & 141,0 & 54,0 & 37,0 & 9,7 \\
\hline
\end{tabular}

$1 \mathrm{VET}=$ valor energético total 
Tabela 5. Adequação nutricional do almoço, em relação às necessidades energéticas do indivíduo-médio, por sexo.

\begin{tabular}{|c|c|c|c|c|}
\hline Adequação & VET (kcal) & Carboidrato (g) & Proteína (g) & Lipídeo (g) \\
\hline Almoço corrigido ${ }^{1}$ & 1108,00 & 141,10 & 53,50 & 36,60 \\
\hline \multicolumn{5}{|l|}{ Sexo masculino } \\
\hline NET SBAN² & 2785,00 & 466,50 & 55,70 & 77,40 \\
\hline NE $40 \%^{3}$ & & 186,60 & 22,30 & 30,90 \\
\hline \multicolumn{5}{|l|}{ Sexo feminino } \\
\hline NET SBAN² & 2056,00 & 344,40 & 41,12 & 57,11 \\
\hline NE $40 \%^{3}$ & & 137,70 & 16,40 & 22,80 \\
\hline
\end{tabular}

1 Corrigido pelo índice de rejeito (6,6\%); VET= valor energético total; ${ }^{2} \mathrm{NET}=$ necessidade energética total; NE = necessidade energética; Percentuais em relação ao VET= carboidratos (67\%), proteínas (8\%) e lipídios (25\%); Fonte: Vannucchi et al. ${ }^{2}$; ${ }^{\mathbf{3}}$ Fonte: Philippi et al. ${ }^{15}$.

\section{I S C U S S Ã O}

\section{Avaliação do consumo alimentar}

O número de cardápios a serem avaliados na determinação do consumo de uma refeição é um fator importante a ser considerado na definição da amostra. No presente estudo, optou-se pela UAN em questão por possuir um padrão definido de estrutura da refeição, servida durante 22 dias úteis. Oliveira et al. ${ }^{11}$ também estudaram 30 cardápios servidos durante o mês, de segunda a domingo, contrastando com outras pesquisas ${ }^{8,10,16}$, cujo número de cardápios foi menor, de 5 a 13.

Dentre as três metodologias de apuração dos ingredientes empregadas no preparo das refeições ${ }^{7,10,16}$, adaptou-se a da pesagem direta dos ingredientes desprovidos das partes nãocomestíveis utilizados nas preparações dos cardápios da UAN, associando-a à determinação do rejeito, parâmetro normalmente não empregado por outros pesquisadores, porém sugerido por Teixeira et al. ${ }^{1}$. Confirmando a constatação feita por Lima \& Gouveia ${ }^{5}$, esta alteração na metodologia realmente acarretou mais tempo na coleta dos dados - 8 horas, pois foi realizada no horário compreendido entre o início do preparo da refeição (7h) e o término de sua distribuição e pesagem (15h).

O levantamento diário das preparações refletiu seu grau de aceitação no cardápio oferecido. Constatou-se que cerca de $85 \%$ das preparações distribuídas eram consumidas (Tabela 2), com uma variação de cerca de $11 \%$. Quando a preparação "iscas de fígado grelhadas" foi servida como opção de prato principal, foi pouco aceita e o consumo per capita foi menor (462g). Em contraste, no dia de maior consumo, foram servidos "bife à milanesa" e "estrogonofe de frango", prato principal e opção de boa aceitação (717g). Portanto, na elaboração do cardápio, o fator aceitação/preferência também deve ser levado em consideração, bem como o registro dos consumos médios diários per capita.

O consumo de bebida, médio total per capita, durante a refeição, foi elevado. Como o consumo total per capita foi de 1,2 copos, com a bebida distribuída em copos de $300 \mathrm{~mL}$, supõe-se que, se fossem utilizados copos de $200 \mathrm{~mL}$, provavelmente o consumo geral seria menor. A clientela da UAN consumiu maior quantidade dos sucos concentrados oferecidos (55\%) em relação aos quatro refrigerantes (45\%), o que denota um hábito saudável, visto que estes sucos são enriquecidos com vitaminas. Entretanto, esse consumo deveria aumentar, se fossem retiradas as opções de refrigerante, que apenas constituem fonte de carboidrato simples. Verificou-se, também, que os consumos de refrigerante light (cerca de 6\%) e do suco diet (2\%) em relação ao total de bebida consumida, foram baixos, provavelmente devido às poucas opções de sabores oferecidos pela UAN, induzindo a clientela a preferir as bebidas adoçadas. Constatou-se, 
também, que o consumo médio per capita de leite foi baixíssimo.

O peso médio do consumo real da refeição per capita (Tabela 3) não apresentou grande dispersão. Este consumo foi cerca de 31\% superior às médias constatadas em restaurantes comerciais self-service por peso - 420g ${ }^{17}$ e $450 g^{7}$. É importante ressaltar que o presente estudo foi efetuado em um sistema self-service total com preço fixo. Neste, o consumo difere daquele observado em self-service por peso, no qual a quantidade da refeição a ser consumida é exibida pela balança eletrônica. No self-service por peso raramente existe o rejeito, pois o cliente paga por ele.

$\mathrm{Na}$ apuração e no controle do consumo alimentar, além da sobra, deve-se também levar em consideração o rejeito. Neste estudo, o índice de rejeito obtido $(6,6 \%)$ foi inferior ao usualmente adotado como padrão; pois só quando for superior a 10,0\% - no caso de se tratar de uma clientela constituída de indivíduos sadios $^{1}$ - pressupõe-se que os cardápios estejam inadequados quanto ao planejamento e à execução. Oliveira et al. ${ }^{11}$ determinaram os índices de rejeito, durante cinco dias consecutivos, em um restaurante com sistema self-service de um hotel, e encontraram valores três vezes superiores ao do presente estudo e ao preconizado por Teixeira et al. . . Embora o tipo de distribuição do self-service desse hotel seja semelhante ao da UAN estudada, supõe-se que os valores superiores, constatados por aqueles autores ${ }^{11}$, sejam justificados pela maior variedade de preparações atraentes oferecidas pelo serviço de hotelaria.

Considerando, ainda, o consumo médio per capita, observou-se que o somatório das sobras e do rejeito da UAN estudada, seria suficiente para alimentar mais 61 clientes, pelo menos, o que representa $20 \%$ do volume médio diário de refeições. Caberia ao nutricionista que gerencia a UAN, programar meios de conscientizar seus funcionários, quanto ao controle das sobras, e sua clientela quanto à diminuição do rejeito, visto que os desperdícios de alimentos refletem e comprometem seu papel na administração dos recursos humanos, materiais e financeiros.

A margem de segurança previsível da quantidade de gêneros alimentícios necessários para atender a possíveis aumentos de consumo, na UAN estudada, foi de $17 \%$ (Tabelas 2 e 3 ) razão percentual do somatório dos pesos da sobra e do rejeito total e o peso da preparação total. Portanto, a quantidade de sobras deve ser relacionada ao número de refeições servidas'. Assim, o peso das sobras nessa UAN pôde ser considerado adequado, pois, ao incluir na previsão o desvio-padrão médio do número diário de refeições servidas e a quantidade do consumo total per capita, resultou em $21 \mathrm{~kg}$ de refeição a mais a ser preparada, valor inferior à quantidade média diária de sobra apurada. No self-service em geral, sempre ocorre o desperdício da sobra, pois todas as preparações do cardápio devem ficar expostas no balcão até o término do horário de distribuição do almoço. O percentual da sobra em relação ao consumo total médio foi de $12 \%$. É relevante ressaltar que, na UAN estudada, mesmo sem empregar os fatores de cocção, o peso da sobra representou aproximadamente $10 \%$ do total preparado. Maior redução nestas sobras poderia ser conseguida mediante a aplicação dos fatores de cocção das preparações ${ }^{1}$, obtidos conforme exemplificado na Tabela 1. Isto resultaria na diminuição correspondente do custo alimentar.

Os pesos médios dos consumos per capita das preparações dos cardápios, decresceram da seguinte forma: pratos protéicos (138g - 23,0\%); saladas (121g - 20,0\%); arroz (115g-19,0\%); sobremesas (85g - 14,0\%); feijão (72g - 12,0\%); guarnição (65g - 10,5\%) e temperos (13g - 2,0\%). Na análise geral do consumo das preparações oferecidas nos cardápios diários constatou-se que algumas delas - feijão, arroz, tomate e hortaliças folhosas das saladas e carne de frango do prato principal - não sofreram grandes variações, visto serem preparações fixas e servidas diariamente, tornando-se hábito alimentar da clientela. As sobremesas, como melancia, mamão, arroz doce, 
doces concentrados e pudim de coco, foram servidas com freqüência, apresentando consumo médio. O consumo registrado foi variável, no caso das várias guarnições, tanto os acompanhamentos dos pratos protéicos, como os temperos e os ingredientes empregados na decoração das preparações ou distribuídos no balcão self-service.

Vale ressaltar a importância da proporção dos consumos simultâneos de feijão em relação ao $\operatorname{arroz}(1: 1,6)$, combinação próxima à adequada para equilibrar os aminoácidos limitantes ${ }^{2}$. Também interpretou-se como hábito saudável, o consumo de frutas - fontes de vitaminas e sais minerais - $16 \%$ superior ao doce. Comparando-se os resultados do self-service aqui estudado, com os dados obtidos por Fausto et al. ${ }^{8}$, observou-se que o consumo total de uma refeição oferecida, porcionada em bandeja estampada, foi superior em $17 \%$. Estes autores analisaram as refeições servidas durante cinco dias na UAN de uma universidade, em Araraquara, SP, e constataram o consumo médio per capita de $711 \mathrm{~g}$, sendo: $109 \mathrm{~g}$ (16\%) de prato protéico; 106g (15\%) de guarnição e também feijão; $201 \mathrm{~g}(28 \%)$ de arroz; $73 \mathrm{~g}(10 \%)$ de saladas e $116 \mathrm{~g}(16 \%)$ de sobremesa. Entretanto, quando comparados os tipos de preparações, a contribuição percentual do prato protéico foi mais elevada (23\%), no sistema self-service aqui estudado, devido aos consumos liberados do prato principal, da opção e dos ovos numa mesma refeição. Ademais, verificou-se que o consumo da salada foi duas vezes superior ao do serviço porcionado citado, denotando um hábito saudável da clientela da UAN desta empresa.

Existe recomendação ${ }^{15}$ de se consumir diariamente, no mínimo, uma porção de prato protéico eqüivalente a $82 \mathrm{~g}$, para indivíduos com necessidade diária de $1600 \mathrm{kcal}$ e duas porções, para os de $2800 \mathrm{kcal}$. Portanto, a quantidade média per capita do prato protéico consumida somente em uma única refeição, superou em 1,7 a recomendação para a classe de $1600 \mathrm{kcal}$ e contribuiu com $84 \%$ da recomendação diária para a de $2800 \mathrm{kcal}$. Além disto, Abreu ${ }^{7}$ constatou, em restaurantes self-service por peso, média de consumo per capita de $154 \mathrm{~g}$ de carne crua com osso. A quantidade média per capita de carne crua, sem osso, utilizada nas presentes preparações, foi de $113 \mathrm{~g}$ para o prato principal e $88 \mathrm{~g}$ para a opção, totalizando 201g. Assim, acrescentando-se $27 \mathrm{~g}$ de osso ao total per capita de carne, esta preparação passa a ter $228 \mathrm{~g}$, ou seja, um valor $48 \%$ superior ao observado nos restaurantes por peso.

É importante salientar que, além do prato principal, utilizaram-se como ingredientes de guarnições, saladas e arroz composto, alguns tipos de carnes, que não foram computados no valor apresentado. Entretanto, esta parcela representaria apenas uma pequena parte do cômputo geral.

\section{Consumo de macronutrientes e fibra alimentar}

Verificou-se que a distribuição percentual, em ordem decrescente, da energia das preparações no VET (Tabela 4) foi igual a: prato protéico (35\%); bebida (20\%); arroz (16\%); sobremesa e guarnição (ambos 7\%); salada e feijão (ambos $6 \%$ ) e tempero (3\%). As preparações que mais contribuíram ao teor de carboidratos da refeição, foram a bebida (38\%), o arroz (26\%) e a sobremesa (11\%). O prato protéico (76\%), seguido do feijão (7\%) e do arroz (6\%) foram os mais ricos em proteínas.

Os valores mais significativos quanto ao teor de lipídios, corresponderam ao prato protéico (57\%), à guarnição e à salada (ambas 10\%) e ao consumo simultâneo de arroz e feijão (total de $12 \%)$.

O feijão (40\%) e a salada (23\%) foram as preparações que contribuíram com os maiores teores de fibra alimentar. Além disto, o teor (sem correção pelo índice de rejeito) de fibra alimentar nas preparações dos cardápios estudados foi cerca de $29 \%$ inferior ao obtido por Fávaro et al. ${ }^{9}-14 \mathrm{~g}$. Entretanto, tanto este resultado, como os encon- 
trados no presente estudo, apresentam teores de fibra alimentar inferiores aos previstos nas recomendações nutricionais²,14. Há, portanto, uma margem deficiente, a ser provida pelas outras refeições.

\section{Adequação nutricional do almoço self service}

As contribuições dos macronutrientes para a NET de $1108 \mathrm{kcal}$ do almoço consumido, foram de $51 \%$ para os carboidratos, $19 \%$ para as proteínas e 30\% para os lipídios (Tabela 5). O percentual da NET correspondente ao almoço do indivíduo-médio do sexo masculino (40\%) atendeu à recomendação ${ }^{14}$, enquanto que o do feminino (54\%) excedeu a recomendação. O maior percentual de contribuição na NET de todo o grupo selecionado, em relação ao VET real médio, foi o das proteínas - 96\% e 130\% para os indivíduos-médios dos sexos masculino e feminino, respectivamente ${ }^{14}$. Este resultado pode estar associado ao fator econômico: o indivíduo-médio tende ao consumo elevado dos alimentos mais caros, já que não existe restrição quanto à quantidade das duas opções de pratos principais servidos. Conclui-se que, o consumo de fontes protéicas no almoço estudado para o indivíduo-médio do sexo masculino e o do feminino, deveria ser reduzido cerca de 2 e 3 vezes, respectivamente, para atender às recomendações ${ }^{2}$.

As contribuições dos lipídios para as NET dos indivíduos-médios, foram 47\% (homens) e $64 \%$ (mulheres), sendo superiores às recomendações ${ }^{2,14}$. Importa ressaltar que, reduzindo-se o consumo de proteínas, os teores de lipídios na refeição também diminuirão, visto que alguns dos pratos protéicos consumidos pelo grupo representativo são ricos em lipídios. Mondini \& Monteiro ${ }^{18}$ já haviam constatado que, na região Sudeste, o consumo relativo de gorduras ultrapassava o limite máximo das recomendações.

Quanto à contribuição do carboidrato para a NET, foi baixa para o indivíduo-médio do sexo masculino $(30 \%)$. O consumo reduzido de carboidratos coincide com resultados obtidos em um estudo da avaliação do comportamento alimentar da população brasileira ${ }^{18}$, em que foram detectadas a diminuição no percentual da participação relativa de carboidratos na dieta e sua substituição por gorduras de origem vegetal, principalmente na década de 80 . Também Abreu ${ }^{7}$ constatou que os clientes dos restaurantes por peso, por motivos econômicos, não escolhem uma dieta balanceada; em geral, negligenciam os carboidratos, cujas fontes são relativamente baratas, mas que, neste tipo de serviço, têm seus preços equiparados aos das outras preparações. Entretanto, a contribuição de carboidratos para a NET do almoço do indivíduo-médio do sexo feminino $(41 \%)$ foi praticamente adequada às recomendações ${ }^{2}$.

Fávaro et al. ${ }^{9}$ analisaram amostras dos 15 almoços da UAN de uma faculdade de São Paulo, SP e obtiveram valores médios de VET igual a $1100 \mathrm{kcal}$, correspondendo a $54 \%$, $19 \%$ e $28 \%$ de carboidratos, proteínas e lipídios, respectivamente. Importa observar que essa UAN possui o sistema de distribuição porcionado por atendentes e apresentou valores próximos aos do self-service da companhia de Santa Luzia (Tabela 5): 51\%, $19 \%$ e $30 \%$ do VET de $1108 \mathrm{kcal}$. Na UAN de uma universidade em Araraquara, SP8, com sistema de distribuição porcionado, foram constatados valores médios superiores para o VET (1 509kcal) e valores diferentes para a contribuição percentual dos macronutrientes, mas houve preponderância dos lipídios (46\% de carboidratos, 9\% de proteínas e $45 \%$ de lipídios) em relação aos resultados encontrados na UAN de Santa Luzia, MG.

O teor de fibra alimentar real consumido no almoço (Tabela 4), pelo indivíduo-médio de ambos os sexos, correspondeu a cerca de $44 \%$ das recomendações ${ }^{2,14}$. Lajolo et al. ${ }^{19}$ ressaltaram que a ingestão média de fibra alimentar solúvel e insolúvel, pela população brasileira, tem diminuído nas décadas de 70, 80 e 90, sendo de 19, 16 e $12 \mathrm{~g} /$ dia, respectivamente, o que parece confirmar-se na análise da presente UAN. Essa ingestão 
pode ser indiretamente avaliada, mediante o levantamento do consumo diário das quantidades significativas de arroz polido, pão francês e feijão ${ }^{19}$. Como no presente estudo só foi avaliado o almoço self-service, cujos percentuais mais elevados de fibra alimentar resultaram da contribuição do feijão (40\%) e da salada (23\%), concluiu-se que a presença deste nutriente é insuficiente nos cardápios do almoço, pois parece improvável que os indivíduos venham a consumir os restantes $56 \%$ de fibra alimentar nas outras refeições do dia. A quantidade de líquidos ingeridos também deveria ser incrementada com a recomendação do aumento do consumo de fibras, pois as fibras insolúveis possuem a capacidade de absorver até 20 vezes seu peso em água ${ }^{19}$. É importante mencionar que o adulto médio elimina 2 a 2,5L de água diariamente ${ }^{2,14}$. Essa reposição no organismo ocorre por meio da água in natura e de outras bebidas; da água pré-existente nos alimentos que são consumidos e daquela produzida pela oxidação celular. Portanto, a ingestão recomendada diária de líquidos é de $30 \mathrm{~mL} / \mathrm{kg}$ de peso corpóreo, cerca de $2 \mathrm{~L}$ para um adulto de $70 \mathrm{~kg}^{14}$ - meta que poderia ser alcançada pela clientela da UAN ao longo do dia.

Considerando que o indivíduo-médio estudado representa a clientela da UAN e comparando os resultados obtidos com aqueles de representatividade nacional populacional ${ }^{4}$, pode-se concluir que o almoço do tipo self-service confirma a ingestão elevada de alimentos com alta densidade energética, principalmente na clientela do sexo feminino, e de gordura, associada ao consumo de carne. Entretanto, o aumento de ingestão de carboidratos (açúcares) não foi confirmado, tendo seu consumo variado de inferior a adequado. Quanto à fibra alimentar, os teores consumidos também foram baixos.

Ressalta-se ainda que todos os nutrientes devem estar presentes em todas as refeições, nas quantidades e percentuais recomendados e levando-se em consideração as NET calculadas com base nas atividades físicas (ocupacional, esportiva e residual), para que a adequação nutricional do indivíduo-médio seja atendida. As atividades de atenção dietética devem anteceder o planejamento de uma refeição adequada, sendo inerentes ao nutricionista responsável, o que não foi priorizado na UAN estudada. Também na avaliação das UAN pesquisadas em Maceió, AL, Seara et al. ${ }^{20}$, constataram que $80 \%$ dos nutricionistas das UAN determinavam as quantidades consumidas de alimentos per capita; $60 \%$ e $70 \%$ calculavam o VET do almoço por preparações, enquanto $50 \%$ apenas o VET por refeições; $50 \%$ estabeleciam as NET da clientela e $40 \%$ avaliavam a adequação nutricional das refeições. Os autores concluíram que, naquelas UAN, as atividades mais desenvolvidas da atenção dietética, eram aquelas indispensáveis à produção em ampla escala e à gestão dos custos.

Na UAN estudada, com sistema de distribuição self-service total, o almoço consumido pela clientela, avaliado pela metodologia da pesagem direta modificado, não foi nutricionalmente adequado. O valor do índice de rejeito apurado $(6,6 \%)$ foi inferior ao considerado como padrão $(10,0 \%)$ para coletividades sadias.

\section{REFERÊ NCIAS}

1. Teixeira SMFG, Oliveira ZMC, Rego JC, Biscontini TMB. Administração aplicada às unidades de alimentação e nutrição. São Paulo: Atheneu; 1997.

2. Vannucchi H, Menezes EW, Campana AO, Lajolo FM. Aplicações das recomendações nutricionais adaptadas à população brasileira. Ribeirão Preto: Legis Suma/Sociedade Brasileira de Alimentação e Nutrição; 1990.

3. Ministério do Trabalho e Emprego. Orientação da educação alimentar. Brasília; 1999.

4. Trigo M. Metodologia de inquérito dietético: estudo do método recordatório de 24 horas [tese]. São Paulo: Faculdade de Saúde Pública, Universidade de São Paulo; 1993.

5. Lima MC, Gouveia ELC. Avaliação nutricional em coletividades. In: Gouveia ELC, editor. Nutrição, saúde \& comunidade. 2.ed. Rio de Janeiro: Revinter. 1999. p.145-8. 
6. Vasconcellos MTL, Anjos LA. Taxa de adequação (ingestão/requerimento) de energia como indicador do estado nutricional das famílias: uma análise crítica dos métodos aplicados em pesquisas de consumo de alimentos. Cad Saude Publica. 2001; 17(3):581-93.

7. Abreu ES. Restaurante "por quilo": vale quanto pesa? Uma avaliação do padrão alimentar em restaurantes de Cerqueira César, São Paulo, SP [dissertação]. São Paulo: Faculdade de Saúde Pública, Universidade de São Paulo; 2000.

8. Fausto MA, Ansaloni JA, Silva ME, Garcia Júnior J, Dehn AA, César TBA. Determinação do perfil dos usuários e da composição química e nutricional da alimentação oferecida no Restaurante Universitário da Universidade Estadual Paulista, Araraquara, SP, Brasil. Rev Nutr. 2001; 14(3): 171-6.

9. Fávaro DIT, Afonso C, Vasconcellos MBA, Cozzolino SMF. Determinação de elementos minerais e traços por ativação neutrônica, em refeições servidas no restaurante da Faculdade de Saúde Pública, USP. Ciênc Tecnol Alim. 2000; 20(2):176-82.

10. Lopes CM, Garcia MLT. Avaliação das refeições servidas em uma unidade da Polícia Militar - cidade de São Paulo. [online] Maio 2000 [acesso 22 maio 2000]. Disponível em: URL:http://www. nutriatuação.ntr.br/pesquisas/aplicada37.htm

11. Oliveira CJ, Barros ICP, Santos AP, Andrade C, Cunha DTO, Assis EM, et al. Determinação do índice de rejeito da refeição almoço para controle de custo no restaurante Hotel Pousada - Pousada do Rio Quente, Goiás [CD-ROM]. In: Resumos do 16o Congresso Brasileiro de Nutrição; 2001; Salvador. Salvador: Associação Brasileira de Nutrição; 2001.

12. Oliveira LF, Silva MF, Santos UC, Pereira DB, Silva VM, Gomes IR. Estudo comparativo entre a ração alimentar e as necessidades calóricas diárias de estudantes em um Serviço de Alimentação Institucional. In: Resumos do 17으 Congresso
Brasileiro de Ciência e Tecnologia de Alimentos; 2000; Fortaleza. Fortaleza: SBCTA/Universidade Federal do Ceará; 2000. 3:7-10.

13. Amorim MMA. Adequação nutricional do almoço self-service de uma empresa do município de Santa Luzia - MG [dissertação]. Belo Horizonte: Faculdade de Farmácia, Universidade Federal de Minas Gerais; 2002.

14. Dutra-de-Oliveira JE, Marchini JS, editores. Ciências nutricionais. São Paulo: Sarvier; 1998.

15. Philippi ST, Latierza AR, Cruz ATR, Ribeiro LC. Pirâmide alimentar adaptada: guia para escolha dos alimentos. Rev Nutr. 1999; 12(1):65-80.

16. Ribeiro MA, Stamford TLM, Filho JEC. Valor nutritivo de refeições coletivas: tabelas de composição de alimentos versus análises em laboratório. Rev Saude Publica. 1995; 29(2): 120-6.

17. Magnée HM. Manual do self-service. São Paulo: Varela; 1996.

18. Mondini L, Monteiro CA. Mudanças no padrão de alimentação da população urbana brasileira (1962-1988). Rev Saude Publica. 1994; 28(6): 433-9.

19. Lajolo FM, Saura-Calixto F, Penna EW, Menezes EW, editores. Fibra dietética en Iberoamérica: tecnologia y salud; obtención, caracterización, efecto fisiológico y aplicación en alimentos. São Paulo: Varela; 2001.

20. Seara LT, Florêncio CQ, Rios KJ, Souza LM. Atividades desenvolvidas por nutricionistas em Unidades de Alimentação e Nutrição na Cidade de Maceió - AL. In: Resumos do 6o Congresso Nacional da Sociedade Brasileira de Alimentação e Nutrição; 2001; Florianópolis. Florianópolis: SBAN/Universidade Federal de Santa Catarina; 2001. p.195.

Recebido para publicação em 15 de julho de 2002 e aceito em 4 de fevereiro de 2004. 